\title{
The Authors' Reply to Allen et al.: "A Comment on Boyers et al.: 'Eltrombopag for the Treatment of Chronic Immune or Idiopathic Thrombocytopenic Purpura: A NICE Single Technology Appraisal'"
}

\author{
Dwayne Boyers $\cdot$ Xueli Jia $\cdot$ David Jenkinson · \\ Graham Mowatt
}

Published online: 27 November 2012

(C) Springer International Publishing Switzerland 2012

Dear Editor,

We (the authors) acknowledge and welcome this letter of clarification from Allen et al. [1]. We would like to justify our use of the alternative (earlier) data, which were presented on the grounds that these were the only publicly available data at the 'time of writing' and indeed acceptance of the article for publication [2]. We are grateful to GlaxoSmithKline for highlighting and making available the revised data. The revised data presented appear robust and analytically valid; however, readers of PharmacoEconomics should be aware that the point estimates of the odds ratios remain favourable to the comparator drug, despite the acknowledged lack of statistical significance, which is not surprising given the small sample sizes used for the analysis. Nevertheless, the response data in question had no effect on the manufacturer's estimation of cost effectiveness, as calculations for the health economic analysis were based on bleed event data, rather than response rates.

We would also like to draw readers' attention to the fact that the appraisal of drugs for chronic immune or idiopathic thrombocytopenic purpura (ITP) is a fast-moving field, with new information constantly being made available. Therefore, we would recommend readers to use our article as a supplement to and summary of the more detailed

D. Boyers $(\bowtie)$

Health Economics Research Unit, Institute of Applied Health

Sciences, University of Aberdeen, Foresterhill,

Aberdeen AB25 2ZD, Scotland

e-mail: d.boyers@abdn.ac.uk

D. Boyers · X. Jia · D. Jenkinson - G. Mowatt Health Services Research Unit, Institute of Applied Health Sciences, University of Aberdeen, Aberdeen, Scotland information available from the National Institute for Health and Clinical Excellence (NICE) website [3], and would also like to draw attention to the ongoing NICE review of eltrombopag [4].

Acknowledgements The views and opinions expressed herein are those of the authors and do not necessarily reflect those of NICE or the Department of Health.

Conflicts of interest Dwayne Boyers completed an internship (3-month student placement in Dublin, Ireland) with GlaxoSmithKline as part of an MSc in Economics from the National University of Ireland (NUI), Galway, during which time he completed a minor dissertation on the supply and reimbursement of medicines in Ireland. As part of the programme between NUI Galway and GlaxoSmithKline, he received a small stipend to cover living expenses while on placement in Dublin in 2009. The remaining authors have no conflicts of interest to report.

\section{References}

1. Allen R, Brainsky A, Grotzinger K, Roccia T. A comment on Boyers et al.: "Eltrombopag for the treatment of chronic immune or idiopathic thrombocytopenic purpura: a NICE single technology appraisal" [letter]. Pharmacoeconomics. 2012. doi:10.1007/s40273012-0003-8.

2. Boyers D, Jia X, Jenkinson D, Mowatt G. Eltrombopag for the treatment of chronic immune or idiopathic thrombocytopenic purpura: a NICE single technology appraisal. Pharmacoeconomics. 2012;30(6):483-95.

3. National Institute for Health and Clinical Excellence. Thrombocytopenic purpura: eltrombopag (TA205). London: NICE; 2010. http://www.nice.org.uk/TA205. Accessed 26 Oct 2012.

4. National Institute for Health and Clinical Excellence. Thrombocytopenic purpura: eltrombopag (rev TA205) [ID589]. London: NICE; 2012. http://guidance.nice.org.uk/TA/WaveR/132. Accessed 26 Oct 2012. 